\title{
Changes in relaxin and prolactin immunoactivities in ovine plasma following suckling
}

\author{
Gillian D. Bryant and W. A. Chamley \\ Department of Anatomy \& Reproductive Biology, School of Medicine, University of Hawaii, \\ Honolulu, Hawaii 96822 , U.S.A., and \\ Reproductive Research Section, University of Melbourne, S.S. Cameron Laboratory, \\ Werribee 3030, Australia
}

Suckling or milking is associated with a marked increase in secretion of hormones from the anterior and posterior pituitary. Plasma prolactin levels rise in response to milking and/or suckling in all the species that have been studied including man (Tucker, 1974).

Little attention has been paid to the secretion of peptides of non-pituitary origin in response to suckling or milking. Relaxin is classically a hormone of pregnancy (Hisaw \& Zarrow, 1951; Porter, 1972), and can be produced in the sheep by either the ovary or uterus (Bryant \& Stelmasiak, 1974). There is evidence that the mammary gland may be a target organ for ovarian relaxin (Zarrow \& McClintock, 1966) and that relaxin may act synergistically with oestrogen and progesterone to develop the mammary apparatus during pregnancy (Harness \& Anderson, 1975). A study was undertaken to determine whether relaxin immunoactivity would respond to an acute stimulus, by measuring plasma prolactin activity as an index of pituitary response to the suckling stimulus.

The experiments were carried out with Merino ewes which had experienced normal pregnancy and parturition, and accepted their single lambs. Blood samples $(10 \mathrm{ml})$ were collected from a jugular vein which had been previously cannulated with a piece of silastic tubing (Dow Corning). Care was taken during the experiments to reduce any possible stress to the animals. Two experiments were carried out. In Exp. 1, two 5-day-old lambs were removed from their dams for over $5 \mathrm{hr}$ and were then replaced and allowed to suck. Samples were collected 23 min before suckling and then every 3 min during the suckling period (Text-fig. 1). Experiment 2 was carried out with 4 ewes when their lambs were 12-15 days old. A blood sample was taken when each lamb was removed from its dam $(-28 \mathrm{~min})$ and a second sample was collected at $-10 \mathrm{~min}$. When the lambs were replaced, suckling commenced immediately and blood samples were collected at 5-min intervals over the next $30 \mathrm{~min}$ (Text-fig. 2).

Relaxin immunoactivity was measured using the technique of Bryant (1972) exactly as described except that separation of bound and free hormone was effected by a conventional double antibody procedure (Bryant \& Stelmasiak, 1974). Levels are expressed as ng porcine relaxin (NIH-R-P1)/ml, since the relaxin-like immunoactivity of sheep plasma paralleled that of this porcine standard. There is no cross-reaction in this assay by any of the known anterior and posterior pituitary hormones at levels of $1 \mu \mathrm{g} / \mathrm{ml}$. The radioimmunoassay of Bryant \& Greenwood (1968) for ovine prolactin was employed with charcoal-dextran separation of bound and free hormone.

The results of Exp. 1 showed that relaxin immunoactivity was low $(<20 \mathrm{ng} / \mathrm{ml})$ before the lambs were replaced (Text-fig. 1). Both prolactin and relaxin immunoactivities rose by $3 \mathrm{~min}$ after the initial suckling stimulus and dropped within $10 \mathrm{~min}$ in both ewes.

The results of Exp. 2 showed that at $-10 \mathrm{~min}$ before suckling there was a prominent rise in the levels of relaxin and prolactin. As the lambs sucked the circulating levels of both hormones were falling, but by 10 min after suckling had commenced relaxin had risen from 15 to $99 \mathrm{ng} / \mathrm{ml}$ and prolactin from 55 to $156 \mathrm{ng} / \mathrm{ml}$ (Text-fig. 2).

Overall mean relaxin immunoactivity was not significantly different in the two experiments, but mean prolactin levels were significantly higher in Exp. 2, possibly because the animals were at a later stage of lactation. Prolactin and relaxin immunoactivities showed a highly significant correlation in each experiment: in Exp. $1 r=0.55$ and $P<0.001$ for Ewe 654, and $r=0.34$ and $P<0.02$ for Ewe 76; in Exp. $2 r=0.76$ and $P<0.001$. 


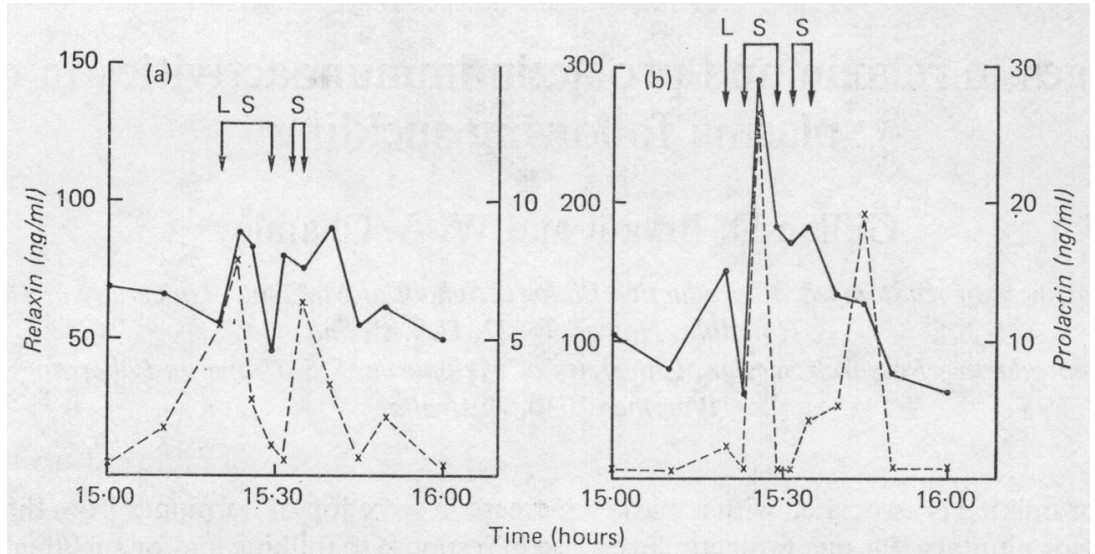

Text-fig. 1. Levels of relaxin (---) and prolactin (-) in (a) Ewe 76 and (b) Ewe 654. The 5-day-old lambs were removed for over $5 \mathrm{hr}$, replaced (L) and allowed to suck. Blood samples were collected every 3 min over the suckling period (S).

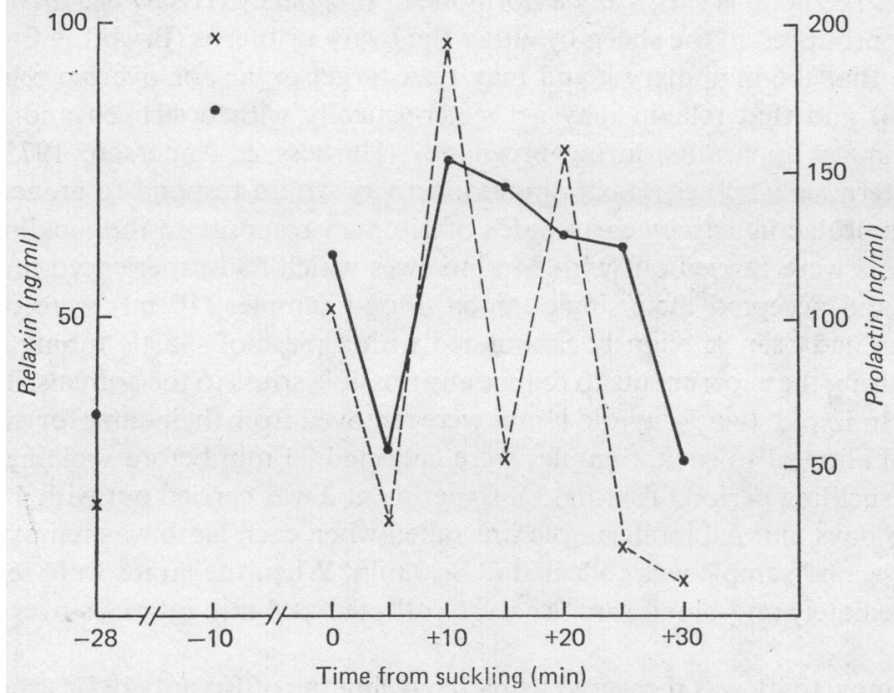

Text-fig. 2. Mean levels of relaxin (---) and prolactin (-) in four ewes with lambs 12-15 days old. Blood samples were taken when each lamb was removed from its dam $(-28 \mathrm{~min})$ and again at $-10 \mathrm{~min}$. The lambs were replaced and allowed to suck, and blood samples were collected every 5 min over the suckling period.

In these experiments relaxin immunoactivity in plasma was elevated as rapidly and consistently as prolactin by the suckling stimulus, and the results therefore show that a peptide hormone which is not of pituitary origin can be secreted in response to suckling. It is not known whether this relaxin immunoactivity originates from the ovaries and/or uterus, since the radioimmunoassay employed cannot distinguish between them (Bryant \& Stelmasiak, 1974), and there is no evidence that ovarian and uterine relaxins are different in structure.

It is premature to conclude that there is a direct causal relationship between the secretion of prolactin and relaxin release, but the relaxin response to suckling could be brought about by a release of oxytocin which then acts upon the uterus. It will be necessary to perform suckling studies with ovariectomized and hysterectomized lactating animals to further investigate the source and mechanism of relaxin release.

We acknowledge the technical assistance of Mrs Nam Soon Joun. This work was supported by grant No. HD 06633, a Ford Foundation grant 66202 and the Cancer Center of Hawaii CA 15655. 
One of us (G.D.B.) was supported by a Reseach Career Development Award, HD 70516 and (W.A.C.) was supported by the Australian Wool Corporation.

\section{References}

BRYANT, G.D. (1972) The detection of relaxin in porcine, ovine and human plasma by radioimmunoassay. Endocrinology 91, 1113-1117.

Bryant, G.D. \& Greenwood, F.C. (1968) Radioimmunoassay for ovine, caprine and bovine prolactin in plasma and tissue extracts. Biochem. J. 109, 831-840.

Bryant, G.D. \& Stelmasiak, T. (1974) The specificity of a radioimmunoassay for relaxin. Endocr. Res. Commun. 1, 415-433.

HaRness, J.R. \& ANDerson, R.R. (1975) Effect of relaxin on mammary gland growth and lactation in the rat. Proc. Soc. exp. Biol. Med. 148, 933-936.
HisAw, F.L. \& ZARROW, M.X. (1951) The physiology of relaxin. Vitams Horm. 8, 151-178.

PORTER, D.G. (1972) Myometrium of the pregnant guinea pig. The probable importance of relaxin. Biol. Reprod. 7, 458-464.

TUCKER, H.A. (1974) General endocrinological control of lactation. In Lactation, a Comprehensive Treatise, Vol. 1, pp. 277-326. Eds B. L. Larson \& V. R. Smith. Academic Press, New York and London.

ZARROW, M.X. \& MCClinToCK, J.A. (1966) Localization of ${ }^{131} I$-labelled antibody to relaxin. $J$. Endocr. $36,377-387$.

Received 23 August 1975 